\title{
INTERCULTURALIDAD, POSIBILIDAD DE ENCUENIRO ENTRE SABERES, SENTIRES Y VIDAS
}

\section{Interculturality, possibility of meeting between knowledge, feelings and lives}

\author{
Omar Fragoso García* \\ Imelda Álvarez García** \\ Jonathan Israel Valdez Regalado***
}

Recibido:29 de septiembre 2020. Aceptado: 02 de diciembre 2020. Publicado: 01 de enero 2021.

Forma de citar este artículo en APA:

Guerra-García, E. (2021, enero-junio). Interculturalidad, posibilidad de encuentro entre saberes, sentires y vidas. Revista CoPaLa, Construyendo Paz Latinoamericana 11 (año 6), p. 96-111. DOI:10.35600.25008870.2021.11.0192, Recuperado desde: http://revistacopala.net/index.php/ojs/article/view/76

\section{Resumen}

Este artículo guía su estudio desde la Investigación Acción Intercultural, la cual permite trasformar las prácticas educativas. A su vez también se utilizó la etnografía intercultural, como método cualitativo para dar cuenta de los hallazgos que arrojo el diagnóstico pedagógico, recuperando los tipos de relaciones que se generan entre docentes y estudiantes, priorizando la importancia de las relaciones entre el yo docente y ese otro diferente, el estudiante; por tanto, se visibiliza la posible ausencia de reconocimiento y valoración de ese otro como alteridad. El análisis se desarrolla a partir la interculturalidad funcional, desde la perspectiva interculturalidad crítica planteada por Walsh (2009), y desde los estudios de paz integral de Sandoval (2014). Se concluye, que la interculturalidad como posibilidad de encuentros e intercambio de sentires y pensares, entre la unidad docente-discente, conformada desde el diálogo, el respeto y reconocimiento por el otro; crea relaciones educativas más justas y armoniosas.

Omar Fragoso-García

omaroso2101@gmail.com

Licenciado en Educación Física, egresado de la Escuela Normal de Ecatepec. Maestrante del Posgrado Interculturalidad para la Paz y Conflictos Escolares, por la Escuela Normal de Ecatepec. Cofundador y coordinador de la Banda Juvenil de Marcha "Jaguares MCH" de la Escuela Secundaria 0946 "Mártires de Chicago". Docente en educación secundaria.

\section{** Imelda Alvarez-García}

iimeld@hotmail.com

Licenciado en Psicología Clínica, egresada del Centro Universitario Valle de Anáhuac. Maestra en Tecnología y Ciencias de la Educación. Dra. en Educación por la Universidad IEXPRO. Profesora de la Escuela Normal de Ecatepec. Participante de la línea de investigación "Interculturalidad conflictos y paz, en contextos educativos diversos", del departamento de Posgrado de la Escuela Normal de Ecatepec. Catedrático del Centro Universitario Valle de Anáhuac.

\section{*** Jonathan Israel Valdez-Regalado}

profr_jonathanisrael@hotmail.com

Licenciado en Educación Secundaria con especialidad en Biología y Química, por la Escuela Normal de Tlalnepantla. Maestro en Ciencias de la Educación. Profesor y Pedagogo A en la Escuela Normal de Ecatepec. Participante de la línea de investigación "Interculturalidad conflictos y paz, en contextos educativos diversos", del departamento de Posgrado de la Escuela Normal de Ecatepec. 


\section{Palabras clave}

Interculturalidad, Vínculos, Subalternidad, Paz integral.

\section{Abstract}

This article guides its study from Intercultural Action Research, which allows transforming educational practices. In turn, intercultural ethnography was also used as a qualitative method to account for the findings that the pedagogical diagnosis yielded, recovering the types of relationships that are generated between teachers and students, prioritizing the importance of the relationships between the teaching self and that student. a different one, the student; therefore, the possible absence of recognition and appreciation of that other as alterity becomes visible. The analysis is developed from functional interculturality, from the critical intercultural perspective proposed by Walsh (2009), and from the integral peace studies of Sandoval (2014). It is concluded that interculturality as a possibility of encounters and exchange of feelings and thoughts, between the teaching-student unit, formed from dialogue, respect and recognition for the other; creates more just and harmonious educational relationships.

\section{Keywords}

Interculturality, Links, Subalternity, Integral peace. 


\section{Introducción}

Este escrito aborda con una remembranza de un joven de 17 años, cuando empezaba tomar conciencia de sus actos, y pretendía ser a toda costa el alumno perfecto, que cumplía con todas sus tareas, el alumno que procuraba asistir lo más impecable a la escuela, aquel estudiante que llevaba todos sus cuadernos y libros, aun si fueran no requeridos; el estudiante al que todos le tenían envidia por sus calificaciones, el que no salía al receso por hacer la tarea en el aula, aquel que pretendía no tener amigos para no hacer enojar a los maestros, el estudiante que intentaba cumplir con todo con tal de ser y satisfacer la expectativa de los profesores.

Hay que mencionar que, como estudiante, jamás cuestionó a ningún profesor, siempre acataba ordenes e instrucciones, es posible que influyera la educación que recibía en casa, un tanto agresiva (en ocasiones era golpeado, si respondía de "mala” manera, o no quería hacer la tarea incluso por desobedecer en al modo); ahí también se le enseño que el profesor siempre tiene la razón, porque él es el único que conoce y sabe de educación. Por tanto, esta creencia se mantuvo en su cabeza, al considerar que los docentes enseñan lo que el programa demanda, sin detenerse a pensar si sus enseñanzas eran lo suficientemente comprendidas por quien o quienes asisten a su clase.

Es posible pensar que una historia como esta, también refleja la experiencia de más de un estudiante, desde luego con la misma creencia; que el profesor tiene la razón en el aula y nunca se equivoca, porque conocen todo y saben de todo; sin embargo ¿Cuántos de ellos se preocupan, por lo que sus estudiantes quieren saber? ¿cuántas veces se han cuestionado por lo que sienten sus estudiantes? Y por último ¿cuántas veces se han planteado situaciones más allá de las calificaciones, de la entrega de trabajos o situaciones administrativas a cumplir, que del propio bienestar de sus estudiantes?

El hablar de lo que quiere o siente un alumno no es sencillo, y mucho menos en el nivel secundaria, y más aún, si se atienden grupos de estudiantes tan numerosos. Si bien, existe el compromiso por ejercer la práctica docente, con el único objetivo en mente, que los estudiantes adquieran conocimientos y muestren resultados favorables en cada asignatura y con el principio de realizar todos los productos de aprendizaje planeados y solicitados por cada sesión. Porque el docente ve sólo una ganancia educativa, si el estudiante cumple con todas las tareas asignadas ¿Acaso estos hechos, los hacen ser mejor docente? o ¿será el hecho, que un estudiante al tener más sellos o firmas de control que otro compañero, lo hace mejor estudiante y con ello mejor persona? 
Como docentes, retribuir los problemas de la carga administrativa no justifica el hecho de ser de una manera u otra con los estudiantes; sin embargo, sí influye, el estar con ellos. Porque el estar, no solamente significa estar presente físicamente. El estar requiere dialogar, hacerse visible e interactuar con ellos; así como ocuparse por sus inquietudes. Esto posibilita saber lo que ellos desean, lo quieren conocer, lo que necesitan aprender; y no enseñar lo que el docente cree y quiere que aprendan. Hay que reconocer que los estudiantes también tienen aspiraciones de ser y de crear cosas por ellos mismos; que la labor docente, no es solo facilitar el conocimiento, sino en ofrecer alternativas que favorecerán su desarrollo como seres humanos, por tanto, valorar las alternativas que ellos mismos generen. Pero ¿Existen condiciones de interculturalidad entre el docente y discente que facilite la comunicación entre ellos?

Cuando se habla de interculturalidad probablemente se enfoca pensar que algo o alguien es diferente, ajeno a lo normal; o bien que la "inclusión" de esa diferencia se interpreta como desigualdad con necesidades especiales, en función de adaptarlo a lo que se concibe como ideal o común, y es precisamente de esta premisa de donde se parte este cuestionamiento, y señala hacia dónde se lleva el concepto de la interculturalidad.

Si se parte del principio en donde la interculturalidad es aceptar las diferencias pero todos debemos adaptarnos en espacios de convivencia determinados, entraríamos en la funcionalidad del mismo concepto; es decir que "la interculturalidad funcional asume la diversidad cultural como eje central, apuntalando su reconocimiento e inclusión dentro de la sociedad y el Estado nacionales (uni- nacionales por práctica y concepción) y dejando por fuera los dispositivos y patrones de poder institucional-estructural -las que mantienen la desigualdad..." (Walsh, 2009, p. 9). En esta circunstancia, al vislumbrar a los alumnos como diferentes cada uno con necesidades independientes, pero con la finalidad de encaminarlos hacia la misma dirección; hacia la inserción a la sociedad, apegados a normas del deber ser dentro de la misma sin tomar en cuenta sus propias expectativas e ideas, dista mucho de una verdadera interculturalidad a favor de su persona, de ahí las siguientes cuestiones ¿Dónde queda la interacción y el acercamiento mutuo? ¿en qué momento se les reconoce a los estudiantes como personas, como seres pensantes y con afectaciones? Tendremos que voltear la mirada hacia otro tipo de saberes, del trato para con los otros, si realmente pretendemos encausar la enseñanza para un mundo con los demás, para un cuidado del otro.

La interculturalidad desde un posicionamiento crítico nos da las expectativas y esperanzas para mirar a los otros no como ajenos, si no, de partir el trabajo desde ellos, con ellos, en colaboración para un bien común, totalmente contrario a la visión funcional, así como lo enuncia Walsh (2009), "El interculturalismo funcional responde a y parte de los intereses y necesidades de las instituciones sociales; la interculturalidad crítica, en cambio, es una construcción de y desde la gente que ha sufrido una historia de sometimiento y 
subalternización". En este caso la subalternización se ve reflejada en la posible imposición de un deber ser institucional, donde el estudiante al no tener y carecer de saberes debe aprender; y el profesor como poseedor de conocimiento, debe formar. Pero a su vez el profesor se ve sometido también por imposiciones culturales, a transformar su práctica docente, y por supuesto, que de total satisfacción a la institución donde labora, asumiendo esta práctica de subalternidad, de la misma forma con total normalidad. Sin embargo, las acciones cotidianas de sometimiento entre la relación docente-discente dejan de lado lo importe que es para el docente dialogar e implicarse con su(s) estudiante(s), y con ello ponerse en el lugar del otro (Córdoba Y Vélez-De La Calle, 2016).

A pesar de normalizar los roles de subalternación en la escuela, incluso los actos que parecen "buenos" terminan enclaustrando un sentido de violencia en el actuar de los profesores, que probablemente terminan por reproducir los estudiantes entre sus pares. Bajo este señalamiento se cuestiona ¿Quiénes son los verdaderos actores de la educación? ¿bajo qué significado actúan cada uno? ¿cuál es la función de la escuela? ¿cuál es la función de los profesores y de los estudiantes? ¿Cuál es el lugar del estudiante ante la realidad que se construye cotidianamente dentro de los espacios escolares? y bajo la mirada intercultural crítica ¿Qué tipo de relación se puede construir entre docentes y discentes, que permita valorar la dignidad humana?

Por otra parte, hemos de recordar que este estudio nace en una escuela secundaria, situada dentro de su localidad como una de las más demandada, de acuerdo con la supervisión escolar de la zona. Demostrar esto es fácil, basta con observar los salones sobresaturados, con una cantidad de alumnos que van de los 50 a los 55 por salón (en un espacio de superficie de $36 \mathrm{~m}^{2}$ ), en los tres grados y los cuatro grupos por grado; desde luego en ambos turnos. Además, cuenta con una larga lista de espera solicitando un lugar para ingresar. Por esta razón, el siguiente cuestionamiento, ¿Tener en las escuelas salones de clase saturados (de estudiantes), permite generar vínculos entre los docentes y los estudiantes? Según la Organizaciónón para la Cooperación y el Desarrollo Económicos (OCDE), señaló que esto no es posible, dados los resultados obtenidos por la Encuesta Internacional sobre Docencia y Aprendizaje (TALIS); al informar que los maestros utilizan el $22 \%$ del tiempo efectivo de cada clase para mantener el orden, realizar tareas administrativas y llevar a los alumnos a un estado mental en el que sean receptivos al material didáctico; es decir, utilizan 26 minutos de un bloque total de 100, para organizar la clase y así poder enseñar; cabe marcar, que en el mismo estudio se determinó que estos tiempos se multiplican cuando la clase está sobrepoblada (García-Bullé, 2019); considerando lo anterior, ¿Cómo visibilizar la interculturalidad en las aulas, si el docente no percibe las diferencias? 


\section{La ruta de encuentro}

Este artículo es un fragmento de una investigación más amplia, perteneciente a la línea de investigación "Interculturalidad conflictos y paz, en contextos educativos diversos", coordinada por el departamento de Posgrado de la Escuela Normal de Ecatepec. El escenario que da lugar a este estudio es el nivel secundario de educaciónn básica, propiamente en las aulas durante las sesiones de clase; en el cual los dos actores principales se identifican en los estudiantes y docentes, teniendo como eje de observación y análisis las relaciones que en ellos existen. Cabe señalar que la metodología que guía esta indagación es la Investigación Acción Intercultural, la cual permite cambiar prácticas educativas y relaciones en la comunidad escolar que afectan la convivencia armónica (Sandoval, 2018, p. 78).

Por otra parte se ha de mencionar que en esta investigación cualitativa, se presentan los primeros hallazgos del diágostico pedagógico ; el cual para documentar la relación docente discente se recupero el enfoque de la etnorafía intercultural :

Se realiza de manera directa con los sujetos u objetos de estudio, es decir, que tiene como base el trabajo de campo; reporta realidades objetivas y subjetivas relacionadas con las perspectivas de paz; cuestiona lo investigado a través del giro epistemológico propio del paradigma de los estudios para la paz; mantiene explicita la orientación de conocer las concepciones y las prácticas de paz, los conflictos, las violencias, la interculturalidad para la paz, la democracia, los derechos humanos. etc. (Sandoval, 2018, p. 54)

Desde esta perspectiva, para comenzar con el diagnóstico de la investigación, se analizaron dieciocho videograbaciones de los docentes de matemáticas, español y formación cívica y ética y de los propios estudiantes dentro de los horarios de clases, de una escuela secundaria del municipio de Ecatepec; el registro se realizó a partir de las videograbaciones realizadas desde las cámaras de seguridad instaladas en cada uno de los salones. Las videograbaciones se realizaron en tiempo real, con autorización previa, desde la oficina de dirección, donde se monitorea lo que sucede entre los docentes y discentes. Las acciones de los personajes educativos se sistematizaron a través de un registro, mediante un sistema descriptivo de observación, que de acuerdo con Wittrok, este enfoque de la observación permite describir y analizar con profundidad y detalle los acontecimientos en curso y las conversaciones contenidas en los acontecimientos, y explorar el grado en que son comparables los acontecimientos, las observaciones y demás (1989). Por lo tanto, las observaciones se recuperan al analizar las conductas que muestra el docente al impartir su clase; así como el comportamiento de los estudiantes durante toda la sesión de cada una de las asignaturas que ya se mencionaron. De esta manera nos permite identificar patrones de conducta dentro de las secuencias en curso, verificar los patrones identificados a través de distintos momentos y situaciones y analizar los datos desde diversas perspectivas complementarias (Wittrok, 1989). 
Para poder Identificar los registros de observación se utilizan claves que señalen la recuperación de lo observado (DO), que se obtuvieron y concretaron incidencias de patrones que denotaron una manera de relación con los profesores seleccionados y los actos educativos. Posteriormente se llevó a cabo la sistematización de dichas incidencias. Esto permite dar cuenta de los tipos de relaciones que se generan entre docentes y estudiantes, situación que pudo dar pie a la construcción de categorías dentro de la investigación; priorizando la importancia de las relaciones entre el yo docente y ese otro diferente, el estudiante; en este artículo se visibiliza la posible ausencia de reconocimiento y valoración de ese otro como alteridad.

\section{El estudiante, lo imperceptible del aula.}

La escuela como espacio educativo ha sido escenario de innumerables historias de interacción entre estudiantes y su coprotagonista áulico el docente; desde la perspectiva de este estudio lamentablemente han sido en su gran mayoría de terror. Se mencina asi, por la atmosfera, al clima opresivo que se gesta ante el uso del poder y la autoridad ejercida ante $e l$ o lo vulnerable, y ante todo como la irrupción de temores primales, que fungirán en los estudiantes como basamento de sentimientos de disgusto, culpa, vergüenza, desconfianza; de miedo e inseguridad (Lovecraft, 2020). He de reconocer que en su mayoría el contexto familiar colabora, sin embargo, la figura docente tiene una formación profesional a diferencia de los padres.

...los docentes fueron concebidos como trabajadores y después como profesionales; y en segundo lugar su preparación fue definida como entrenamiento, y más tarde sustituida por educación y desarrollo profesional. Cabe destacar que las repercusiones de este cambio de paradigma fueron significativas, ya que cambiaron las estructuras de las escuelas y las instituciones de formación docente, modificándose también la interacción entre ambas. Por último, plantea el tipo de conocimientos, habilidades y actitudes que deben tener los docentes, y finaliza con recomendaciones generales para educadores........(UNESCO, 2002, p. 8).

Considerando que los docentes poseen una formación profesional que parte del obtener conocimientos, habilidades y sobre todo actitudes; porque entonces generar entre sus estudiantes relaciones ambiguas, cargadas de menosprecio e indiferencia hacia sus alumnos por considerar por tradición que son ellos quienes no saben y requieren ser enseñados.

La siguiente observación forma parte de un hecho cotidiano más amplio relatado en la sesión de la clase de matemáticas en el turno vespertino, han transcurrido veinte minutos desde que el profesor comenzó su clase:

"18:53 hrs. Vuelve a dictar desde el frente del salón de clases, con las manos dentro de las bolsas del pantalón; observa las libretas, no hay contacto visual con los alumnos en ningún momento. Continúa dictando indicaciones por al menos tres minutos, regresa a su teléfono. Una persona levanta la mano, él no lo nota, retoma el dictado, camina de un lado a otro al frente del salón. Pide un cuaderno, lo observa y lo regresa inmediatamente, continua el dictado” (DO1, p. 20). 
Lamentablemente, es común ver en los docentes de nivel secundaría conductas que muestren la carencia de un vínculo afectivo, como se observó en la actitud del profesor de matemáticas por mirar las libretas de los estudiantes, incluso cada vez es más notorio presenciar durante la clase sentimientos tan terribles como la apatía; que al parecer fue lo que sintió el docente, cuando evita el contacto visual hacia sus estudiantes. Así como el espantoso hecho de ignorar a alguien que desea comunicarse con él, al extender su mano hacia el techo y no poder ser visibilizado por su profesor. Esta actitud de indiferencia, de desdén, no es más que la proyección de los pensamientos, anhelos y deseos del yo docente, por el otro yo estudiante; este Alter Ego, el otro (estudiante) es visto como otro yo (docente), donde sus diferencias, o cualidades que el otro posee, son anuladas o despreciadas por el yo (Córdoba y Vélez-De La Calle, 2016).

En los salones de clase se observan diferentes comportamientos, resultado de las relaciones humanas que ahí se gestan, es decir, se aprecian distintas formas de vincularse entre el docente y su estudiante (Dalton, 2007). Desde este estudio los vínculos de afectación son los que sobresalen, y de manera particular, son los vínculos inspirados desde la indiferencia y desatención por el otro distinto a mí, ya sea por ser inexperto, carente de conocimiento o por requerir disciplinamiento; al parecer en la escuela analizada son suficientes cualidades para ser ignorados. Desde este comentario se estudia el siguiente fragmento que recupera la realidad que nos permitirá reforzar los descubrimientos anteriores.

Se observa a la profesora de formación cívica y ética, del turno vespertino:

16:33 hrs. Se levanta para seguir llamando a los alumnos. Ella espera de pie para que los alumnos lleguen hasta ella. En todo momento observa su lista y al cuaderno de los estudiantes, jamás levanta la mirada. 16:37 hrs. Sigue pasando lista con la muestra de los trabajos, los alumnos se mantienen trabajando en su libro, ella no se ha movido de lugar para recibir tareas. Una niña se pone de pie para tirar basura, ella le dice que se siente (DO1, p. 4).

Los vínculos afectivos en la relación docente-doscente, se consolidan de manera principal con el afecto mutuo, y son más sólidos cuando el respeto, la solidaridad y la empatía están presentes a través del diálogo que se forme entre ellos. Sin embargo, la distancia o el espacio delimitado, como lo muestra la docente al estar de pie en una zona que ella estableció, para poder desde ahí establecer su figura de autoridad. Son condición que no permiten anclar la empatía en las relaciones áulicas, ni mucho menos se fortalecen cuando un docente muestra su poder y autoridad, sin revelar rasgos de interés cuando una de sus estudiantes se paró de su asiento para ejercer una posible necesidad física. Vincular de esta manera el yo docente, con el ser estudiante, y quedando (permaneciendo) el otro irremediablemente contenido en el contexto del no-ser, de no existir, como si el estudiante fuera imperceptible a los ojos y oídos del docente, mostrando con esto desinterés e indolencia por alguien que aparentemente está parado cara a cara, en frente de él o ella (Etchebehere, 2010); denotando la ausencia de alteridad y con ello la imposibilidad de construir encuentros de diálogos, de saberes y relaciones humanas a través del sentir y afecto mutuo. 


\section{Cosificación del estudiante desde las exigencias institucionales}

Hablar del proceso de enseñanza-aprendizaje resulta un acto de profundidad, en donde la interacción entre docente y discente se integra como punto clave en este trabajo; no obstante, el concebir tal dinámica solo como un acto de transferencia de información, podría no resultar como una actividad del todo favorecedora para que se propicie la interacción. Interacción que es necesaria, si se parte del supuesto de la interculturalidad crítica, donde planteamos las intervenciones desde los mismos actores subalternizados, en este caso los alumnos, al ser invisibilizados por la figura de autoridad, el docente.

Es decir, si pretendemos entender la función del docente como un guía para la producción de conocimiento y el pensamiento crítico, poco nos acercamos si en su momento la dinámica en las clases se vuelve rutinaria o nos remitimos a funciones tradicionalistas de enseñanza, como lo menciona la SEP (2018):

La educación no debe ser estática. Ha de evolucionar y responder a las características de la sociedad en la que está inserta. Cuando la educación se desfasa de las necesidades sociales y ya no responde a estas, los estudiantes no encuentran sentido en lo que aprenden, al no poder vincularlo con su realidad y contexto, pierden motivación e interés, lo cual se convierte en una de las principales causas internas de rezago y abandono escolar. (p. 28)

En la mayoría de los salones de educación secundaria los docentes como lo hemos observado, utiliza lo que para ellos es el mejor método tradicional de enseñanza, conocida como clase magistral, desde esa técnica el profesor dicta monótonamente sus apuntes un año tras otro y los alumnos no levantan la cabeza, ni quitan los ojos del cuaderno o del libro de texto, según sea el caso (Mirrales, 2015). Desde esta arista, analicemos los siguientes registros de observación.

Es la sesión de matemáticas en el turno vespertino, han transcurrido veinte minutos desde que el profesor comenzó a dar la sesión, cuando llegó, asignó trabajo en el libro y dio algunas indicaciones para trabajar en el cuaderno de los alumnos:

18:40 hrs. Los alumnos continúan trabajando, el profesor revisa su libro, se dirige a la puerta, se recarga en ella y dirige su mirada para observar a los alumnos, permanece ahí un momento, aproximadamente cinco minutos. Intenta prender el proyecto, al parecer no lo logra. Se dirige hacia la puerta, ahí permanece y desde ahí dicta. Coloca sus manos dentro de las bolsas del pantalón, camina y pasa entre las filas, y continúa dictando. Toma la libreta de un alumno sin avisar y de nuevo explica la actividad con el cuaderno. Termina la explicación, toma su celular y se mantiene en la entrada, toma su teléfono celular y comienza a digitalizar, aproximadamente por 15 minutos (DO1, p. 20).

Lo que pareciera ser una clase preparada, planeada, termina en la simplicidad del dictado y la instrucción metódica para realizar las actividades; como se destaca en el relato, el profesor puede tener toda la disposición para utilizar diferentes recursos didácticos y pese a eso, cae nuevamente en lo que mejor sabe hacer una clase repetitiva, memorística, aburrida y, sobre todo, continua reproduciendo la subalternidad de los estudiantes a partir del tipo de interacción que el docente promueve. La imposición de la perspectiva del que sabe, del que 
tiene el poder a partir del dictado. Reiterar que no hay interacción, no hay diálogo, no hay descenso, (aspectos claves para a prender a vivir en diferencia.) Estas interacciones confirman sin duda, lo enraizada que esta la interculturalidad funcional en las aulas escolares, y que la actitud subalterna de los estudiantes responde a las actitudes institucionalizadas que implementa el docente desde su herencia hegemónica (Buiza, 1985).

En la misma sesión de matemáticas en el turno vespertino, han transcurrido cuarenta minutos desde que el profesor arribo al salón:

"19:00 hrs. Pide a los estudiantes que le muestren sus cuadernos, al pasar caminando entre las filas; él solo observa los cuadernos sin exclamar palabra alguna, sólo asiente o niega con la cabeza; pero sigue sin mirar de frente (cara a cara), ni dirigir palabras a los alumnos, retoma su teléfono y a la par revisa las libretas. 19:05 hrs. Pide que pasen a sellar los que terminaron, en cuanto pasan los alumnos, sella inmediatamente el cuaderno y los alumnos regresan a sus asientos sin intercambiar palabras" (DO1, p. 20).

Pese a los tiempo u horas clase que tiene un docente frente a su grupo, son más las actitudes de control disciplinario y de la entrega pronta de los productos de aprendizaje lo que ahí interesa; si bien estas inquietudes o exigencias es lo que se determina o solicita hacerse desde el discurso oficial, son pocos los docentes los que desean o quieren plantear clases verdaderamente significativas y afectivas. Esta actitud es toda una utopía, lamentablemente desde lo que hemos observado, prevalecen los actos simbólicos como son los sellos y firmas, para matizar sutilmente el vínculo de control y subalternidad; o bien ha sido todo lo contrario, de no vivir relaciones humanas afectivas a través del intercambio de sentires, que dignifiquen el buen trato, la aceptación, y el reconocimiento del otro ( $e$ l estudiante); que por ser diferente, ingenuo, juguetón y hasta ocurrente, posee conocimiento para ser intercambiados durante clase o bien en cualquier otro momento de interacción.

....la interculturalidad crítica expresa y exija una pedagogía, y una apuesta y práctica pedagógica que retoman la diferencia en términos relacionales, con su vínculo histórico-político-social y de poder, para construir y afirmar procesos, prácticas y condiciones distintos. De esta manera, la pedagogía se entiende más allá del sistema educativo, de la enseñanza y transmisión de saber, y como proceso y práctica sociopolítico productivo y transformativo asentado en las realidades, subjetividades, historias .... (Walsh, 2009, p. 13).

Las relaciones humanas que se viven en un salón de clases, requieren de praxis pedagógicas, que faciliten el intercambio de conocimiento y con ello posibilitar una interacción entre sujetos valiosos y extraordinarios, con la oportunidad de obsequiar saberes a los otros diferentes y desde esa valía construirse y reconstruirse con el otro; aun cuando esto es una posibilidad, desde la interacción que se ha documentado hasta el momento sólo sean visibilizado prácticas educativas desde la subalternidad y control. Al mismo tiempo es la interculturalidad crítica la que proporciona el basamento para que la complejidad construya métodos educativos distintos para promover vínculos entre la tradición educativa hegemónica del poder (discurso 
oficial) y los métodos de enseñanza que originen el intercambio de saberes a través de la aprehensión y afectación durante los momentos de convivencia entre el yo docente y el otro (estudiante), u lo otro (ambiente) diferente o distinto a él; con el compromiso de construir nuevas realidades juntos y en colaboración partiendo del respeto, la dignidad y empatía del uno por el otro.

Las prácticas de subalternidad que protagoniza un docente indiferente, insensible y desinteresado, que se visibilizan desde esta investigaciónn, lamentablemente son prácticas docentes normalizadas en la mayoría de las aulas de la institución analisada. Y penosamente, lo que menos se observa y se vive es una interculturalidad, la cual, desde este estudio, se refiere a la presencia e interacción equitativa entre los actores educativo (docente-discente), desde sus diversas culturas y saberes, y a la posibilidad de generar expresiones culturales compartidas, a través del diálogo y del respeto mutuo (UNESCO, 2020); ¿Acaso la interacción desde la interculturalidad, entre el docente y el(los) estudiante(s) son invisibles en un salón de clases?

Una vez más revisemos la interacción en el aula de clases, entre el docente y el alumno:

Es la tercera hora de clase del turno matutino, la cual empieza a las 9:30 hrs. La profesora de español llega tarde por 7 minutos a su sesión. Se dirige rápidamente al escritorio, mueve a los alumnos a su paso para llegar. Enseguida se sienta y comienza a tomar asistencia. 9:46 hrs. Sentada comienza a revisar su libreta y un libro. Un alumno se acerca, lo manda a sentar enseguida. 9:49 hrs. La profesora se percata que un alumno se levanta de su lugar y se dirige hacia otro compañero, y le grita que se vaya a sentar a donde le corresponde. La profesora sale del salón (DO1, p. 14-15)

Desde la vida cotidianidad del docente, se puede observar que siempre entre sus manos porta un libro o plumones, incluso varias mochilas todas ellas cargadas con implementos necesarios para dar o impartir su clase; otra actitud visible de la personalidad docente es el caminar deprisa entre los pasillos y corredores escolares, debido a la demora que presenta por llegar tarde al plantel o por realizar tarde el cambio entre cada clase, en fin la justificación de la tardanza por cubrir sus horarios es inagotable. A pesar de esta condición tan humana, de impuntualidad, no se justifica el hecho de ser insensible ante sus estudiantes y no brindarles un saludo matutino que denote empatía hacia ellos, por protagonizar un acto irrespetuoso e irresponsable al llegar tarde a su compromiso académico. No obstante, a esa indiferencia, y no mostrar simplicidad por el incumplimiento a su labor docente, continúa protagonizando actitudes autoritarias, gritando dentro del aula para exigir el orden y control que requiere poder ejercer su trabajo. Por tanto, estas prácticas docentes distan de contener principios de interculturalidad, al anular la interacción equitativa que pide y sugiere el estudiante, al provocar encuentros de diálogo en cualquiera de sus formas, incluso al caracterizar físicamente obstáculos dentro del salón de clases, como pretexto para ser visto y sentido (tocado); y con ello provocar a un más llamar su atención del docente, cuando también utiliza nuevamente su cuerpo para expresar simples movimiento 
estereotipados, como es el clásico impulso de levantarse de su asiento sin tener un destino pensado, con el único propósito de generar cualquier tipo de diálogo o interconección entre él y el otro (docente).

Si partimos de saber que las personas requieren de socializar para aprender, es importante también reconocer que la cultura desde su acumulado de saberes, pensares y haceres, definitivamente constituye en los individuos y en sus pautas de comportamiento; así como las múltiples relaciones que surjan entre ellos (Salazar, 2017). Por consiguiente, considerar las relaciones personales como cualquier resultado que surja del intercambio de saberes, pensares o haceres, entre los individuos; hay que también considerar que la cultura en sí misma no estereotipa las relaciones entre los individuos, simplemente las provoca. Desde este preámbulo es posible comprender que las prácticas docentes que hemos observado cargadas de indiferencia, intolerancia, irresponsabilidad y autoritarismo, son el resultado de una herencia acumulada de tradiciones y de la falsa creencia que es la mejor actitud para enseñar y transmitir conocimiento. Cabe aclarar que todo lo mostrado en este estudio, sólo ha sido analizado desde esta mirada, sin efectuar un acto de intervención para transformar hasta ahora; es decir, sólo se han develado las prácticas docentes. Este trabajo pretende sensibilizar al docente para que vaya en busca de nuevos encuentros de saberes, de pensares y comience su propia introspección, bajo una nueva forma de mirar(se) con y desde la perceptiva del otro; y además que esta decisión surja desde la interacción armoniosa entre el yo docente y el otro, al comenzar a experimentar y sentir nuevas formas de dialogo que enriquezca y fortalezca a la unidad docente-discente (Córdoba \& Vélez-De La Calle, 2016).

Desde esta perspectiva, cómo generar crisis en el docente que provoquen el cambio y cree nuevas formas de relacionarse con el(los) estudiante(s), con la posibilidad de romper con la monotonía y en especial con la no existencia y subalternidad; y con ello dejar de hacer lo que se venía haciendo por creencia, para empezar hacer algo diferente, distinto y así contribuir al fortalecimiento de las relaciones socioeducativas en las aulas (Paradiso, 2013), ¿Será la Alteridad la que propicie el cambio en las prácticas docentes?

Aun cuando planear y organizar la sesión de clase, implica tiempo y conocimiento por parte del docente, y de manera primordial requiere desde la interculturalidad (Cornejo, 2012); ofrecer un acompañamiento al acto educativo que rompa con las inercias en las actividades de aprendizaje al organizarlas en distintas formas, a modo de que todos los estudiantes puedan acceder al conocimiento (SEP, 2017). Observemos el siguiente registro:

Regresa hacia la computadora y continúa dictando. 10:15 hrs. Toma algunas cosas de la lapicera de una alumna (que está cerca de ella). Se las devuelve sin preguntar o decir algo. Vuelve a tomar su teléfono, lo revisa y continúa dictando. Regresa a sentarse. Habla desde su lugar con un alumno que está a distancia de ella. Revisa su computadora, pero sigue dictando. Los alumnos permanecen sentados, escribiendo sin hablar (DO1, p. 14-15). 
Esto desde la organización de una planeación educativa, parece tarea fácil que el docente ofrezca acompañamiento al estudiante en las distintas actividades de aprendizaje; empero, desde la realidad de un salón de clases estas son prácticas invisibles. Y actitudes como dictar los temas para que los estudiantes escriban en silencio sin emitir palabra, o negar la posibilidad de conocer o tomar en cuenta sus puntos de vista, sus intereses o la forma de conceptualizar el mundo, son las prácticas que en realidad se visibilizan continuamente. Esta ausencia de alteridad, al negarse el docente la oportunidad de escuchar opiniones de sus estudiantes, y el impedir el intercambio de nuevas ideas; también imposibilita que exista entre ellos, una interculturalidad para la paz que considere el reconocimiento al otro, desde el valor del diálogo para mostrar cómo pueden implicarse juntos a través de sus relaciones socioeducativas (Sandoval, 2014). Pero ¿Por qué implicar la relación docente-discente desde la interculturalidad para la paz?

Cabe destacar y explicar que la "interculturalidad para la paz, tiene como principio el diálogo respetuoso, igualitario y de relación horizontal entre las diferentes culturas. Una interculturalidad para la paz que considera que reconocer al "otro" y valorar el diálogo entre ellos, tiene su importancia y es un incuestionable principio de ética intercultural" (Sandoval, 2014). Desde esta expresión, se comprende porque la interculturalidad para la paz da la oportunidad de crear nuevas formas de relacionarse desde la horizontalidad del trato respetuoso e igualitario entre el otro docente, y ese otro diferente discente; con la ayuda del diálogo que facilita la escucha y la interacción de sus creencias y conductas. Vale decir, que estos encuentros permiten experimentar diferentes tipos de sentires y pensares, a través del reconocimiento del otro; cuando el docente se da la oportunidad de formular preguntas curiosas, ocurrentes para generar inquietudes en el(los) estudiante(s) y con la disposición de escuchar de todo, siempre y cuando ayuden a la adquisición de nuevos aprendizajes, la relación docente-discente ahora se crean desde la confianza, la tolerancia, el trato digno e igualitario que da la estima mutua.

Convivir en espacios escolares desde contextos interculturales, dan la oportunidad que los actores educativos docente-discente, de-construyan su forma de relacionarse entre sí, al demostrar que el compartir sus saberes y pensares, tienen el afecto y aprecio para crear nuevas formas y sistemas de diálogo; reconociendo el poder que poseen para construirse y transformarse juntos, desde la equidad de género, la igualdad, la inclusión, la solidaridad, el respeto y ante todo por el deseo de crear nuevas formas para gestionar y resolver problemáticas sociales y ante todo de convivencia (Sandoval, 2016). Esta actitud de cambio y de acción participativa es inspirada por la paz integral, que como proceso de cambio y transformación es parte determinante de un engranaje del colectivo educativo más amplio; y que, mediante la educación para una cultura de paz, corresponde coadyuvar para la convivencia armoniosa, el reconocimiento a los Derechos Humanos y la interculturalidad para la paz. Esperando con esta misma participación integral de escuelas incluyentes, libres 
de discriminación; se visibilice la violencia, la justicia, los derechos y obligaciones, la legalidad y normatividad, la ética y moral (Sandoval, 2014). Podemos entonces comprender que los planteamientos de paz integral invitan a que no se entienda la vida escolar en reducidos aspectos, sino en su muy amplia y compleja totalidad. Invita a que en un salón de clases no busquen culpables, ni víctimas, ni victimarios; invita a que reconozcamos nuestra corresponsabilidad, nuestros derechos y obligaciones asumiendo las consecuencias de nuestros actores, sentires y saberes.

\section{Conclusión}

Los espacios educativos toman vida gracias a las interacciones humanas que ahí se gestan, este pulsar y sentir lo vitalizan el docente y discente; a pesar de esto, de conformar un binomio perfecto, no siempre es así, como lo hemos podido observar. Esta interactividad cargada de construcciones sociales, son precisamente lo que ha permitido que sean los protagonistas de nuestra historia; la cual comienza con la actitud permisiva de discriminación y subalternación a la que ambos son sometidos desde los grilletes invisibles institucionales; basta con que alguno de ellos intente quitárselos para que de inmediato el discurso oficial le recuerden el nivel de calidad y las metas anuales que debe cubrir en su espacio educativo. Como tratar de cambiar esta relación, si el temor es el que se apodera de la razón docente, y nublas las posibilidades de encuentro con otros, diversos a él; y peor aún que prefiera anularlas y en ocasiones a eliminaras por simple supervivencia.

No obstante, el docente y el(los) estudiante(s) desde su naturaleza tan plástica, permite reponerse a todo sentimiento de malestar, de disgusto; con la posibilidad de renombrar sus sentires y sus saberes. Este posicionamiento de la interculturalidad crítica otorga las esperanzas de mirar al otro, desde su importancia, de la valía por colaborar en un bien común. Este reconocimiento por el otro, desde la interculturalidad para paz, como se mencionó inspira al dialogo respetuoso y al trato digno e igualitario, y ante todo al reconocimiento de los Derechos Humanos, junto con cada una de sus obligaciones sociales. Pero entonces como pasar de una dualidad a una unidad docente-discente, y que, además, no sólo de cuenta de una transformación educativa, donde la acción participativa refleje la paz integral, como proceso de cambio, y con ello la transformación de sus relaciones afectivas como rasgo característico de convivir en sociedad.

Si bien, este estudio ha considerado la interculturalidad como posibilidad de encuentros e intercambio de sentires y pensares, y con la oportunidad de aceptarnos desde la diferencia que otorgan los rasgos distintivos espirituales e intelectuales, por medio del diálogo, del respeto y reconocimiento por el otro; y así dirigirnos a relaciones más armoniosas. Este sentir y pensar cualidad única del ser humano no es causalidad, es su naturaleza; es su propósito como un ser de transformación que es, como un ser bioenergético capaz de producir su propia energía. Esta energía toral (que posee el ser humano), que fluye desde un extremo (de su cabeza), 
circula por el centro (al pasar por su corazón) y acaba en el otro extremo (sus pies). Este torrente de energía(sanguínea) esta equilibrada, se autorregula y siempre es completa; y aún más puede extenderse hacia otro cuerpo y juntos pueden expandirse a otros cuerpos, al alternar e intercambiar su energía.

La posibilidad de alternar saberes y sentires, en la unidad discente-docente, a través del intercambio, desde la energía toral, permite desplegar y expandir un sistema autorregulado y en total anomia más duradero; si bien, este evento posee una comprensión más congruente desde las construcciones sociales, la energía toral es el entendimiento del porqué los individuos como seres biopsicosociales podemos visibilizar, reconocer y sentir la paz integral, como resultado de vivir en unión y en relación con el otro o lo otro, construyendo así relaciones más humanas; en otras palabras, con la posibilidad de construir relaciones interbiomagneticas, y por ello transformarnos juntos, y ser uno y en unión con nuestro planeta Tierra, de ser uno y en unió con el universo.

\section{Referencias bibliográficas}

Buiza C. Martínez N. Nieda J. Rodríguez L. Fatima S. (1985). Estudios de Ecosistemas.

Una experiencia de campo y laboratorio. Ministerio de educación y ciencia. $1^{\text {a }}$ Edición. España

Córdoba, M. E. \& Vélez-De La Calle, C. (2016). La alteridad desde la perspectiva de la transmodernidad de Enrique Dussel. Revista Latinoamericana de Ciencias Sociales, Niñez y Juventud, 14 (2), 1001-1015. Recuperado de http://www.scielo.org.co/pdf/rlcs/v14n2/v14n2a09.pdf

Cornejo Espejo J. (2012) Educación, interculturalidad y ciudadanía. Educar em Revista, Curitiba, Brasil, n. 43, p. 239-254, jan./mar. 2012. Editora UFPR. Recuperado de https://www.scielo.br/pdf/er/n43/n43a16.pdf

Dalton M., Hoyle D. G., Watts M, W. (2007) Relaciones Humanas. $3^{\text {a }}$ Edición. México

Etchebehere, P. (2010). Alteridad y vínculos según Viktor Frankl; del alter ego al alter tú. Nous, 14), 1pp. 89.97. Recuperado de: http://logoterapia.net/uploads/14_etchebehere_2010_alteridadyvinculos.pdf

García-Bullé S. (2019) Población y efectividad en el aula, ¿Cuántos alumnos son demasiados? Observatorio. Tecnológico de Monterrey. https://observatorio.tec.mx/edu-news/grupos-grandes-efectividadensenanza.pdf

Lovecraft H. P. (2020) El relato del horror. $1^{\text {a }}$ Edición. Argentina.

Mirralles F. (2015) Amor en minúsculas. $1^{\text {a }}$ Edición. España

Paradiso U. (2013) Protagonistas en Acción. Asumiendo la Vida con Responsabilidad y Transitándola con sentido. Editorial: Dunken. $1^{\text {a }}$ Edición. Argentina.

UNESCO (2002). Formación docente: un aporte a la discusión, la experiencia de algunos países. https://unesdoc.unesco.org/ark:/48223/pf0000131038.pdf 
(2020) Interculturalidad. Artículo 4.8 de la Convención sobre la Protección y la Promoción de la Diversidad de las Expresiones Culturales. Biblioteca virtual. documento de programa o de reunión https://es.unesco.org/creativity/interculturalidad.pdf

Salazar Mastache I. (2017). Conflictos - Pensares, Interculturalidad para la Paz y Gestión en Ambientes. Escolares. -1 ${ }^{\text {a }}$ Edición- Venezuela. Editorial Alfonso Arena, F. P. Año: 2017.

Sandoval Forero E. A. (2016) Educación para la paz integral. Memoria, interculturalidad y decolonialidad. $1^{\mathrm{a}}$. Edición. Colombia

(2014) Educación, paz integral sustentable y Duradera. Universidad Autónoma Indígena De México. Volumen 10 número 2. Edición Especial

http://www.revistapueblos.org/blog/2013/08/12/la-paz-transformadora-una-paz-integral-y-participativa/

(2018) Etnografía E Investigación Acción Intercultural Para Los Conflictos Y Paz. Metodologías Descolonizadoras. $2^{\text {a }}$ Edición, Venezuela.

Secretaría de Educación Pública (2017) Modelo educativo para la educación obligatoria. Educar para la libertad y la creatividad. $2^{a}$ Edición, México. (2018) Aprendizajes Clave para la Educación Integral.

Educación Preescolar. Plan y programas de estudio, orientaciones didácticas y sugerencias de evaluación. Recuperado https://www.siteal.iiep.unesco.org/sites/default/files/sit_accion_files/mx_1150.pdf

Walsh C. (2009) Interculturalidad crítica y pedagogía de-colonial: Apuestas (des)de el insurgir, re-existir y re-vivir. Universidad Andina Simón Bolívar, Ecuador. https://redinterculturalidad.files.wordpress.com/2014/02/interculturalidad-crc3adtica-y-pedagogc3adadecolonial-walsh.pdf

Wittrock M. (1989). La investigación de la enseñanza. Métodos cualitativos y de observación. $1^{\mathrm{a}}$ Edición. Barcelona. 